\title{
Androgen Induces Production of Male Effect Pheromone in Female Goats
}

\author{
Yoshie KAKUMA ${ }^{1)}$, Toru ICHIMARU ${ }^{1)}$, Tomohiro YONEZAWA ${ }^{2)}$, \\ Yukihide MOMOZAWA ${ }^{1)}$, Chie HASHIZUME ${ }^{1}$, Eri IWATA ${ }^{1}$, \\ Takefumi KIKUSUI ${ }^{1}$, Yukari TAKEUCHII), Satoshi OHKURA ${ }^{3)}$, \\ Hiroaki OKAMURA ${ }^{3)}$ and Yuji MORI ${ }^{1)}$
}

${ }^{1)}$ Laboratories of Veterinary Ethology and ${ }^{2)}$ Veterinary Physiology, The University of Tokyo, Tokyo 113-8657 and ${ }^{3)}$ Laboratory of Neurobiology, National Institute of Agrobiological Sciences, Tsukuba 305-8602, Japan

"Present: Department of Animal Sciences, Teikyo University of Science and Technology, Uenohara 409-0193, Japan

\begin{abstract}
Previously we showed that the primer pheromone responsible for the "male effect" was produced in specific skin regions of castrated male goats by androgen treatments. In the present study, we examined whether androgen can also induce production of the male effect pheromone in female goats. Capsules containing dihydrotestosterone (DHT) or testosterone (T) were subcutaneously implanted into six ovariectomized (OVX) goats for 28 days. Small skin samples were collected from the head and rump regions, and the pheromone activity of their ether extracts was examined using a bioassay that monitors the electrophysiological manifestation of the hypothalamic gonadotropin-releasing hormone pulse generator as multiple-unit activity. Behaviors of OVX goats towards ovary-intact estrous goats were also examined before and at the end of DHT or T treatment. Before androgen treatment, neither the head nor rump skin samples in OVX goats showed pheromone activity. DHT treatment induced pheromone activity in the head skin sample of six OVX goats and in the rump skin sample of two OVX goats. Similar results were obtained by T treatment. In addition, OVX goats treated with $\mathrm{T}$ showed masculine-type sexual behaviors such as courtship and mounting behaviors towards the estrous goats. These results demonstrate that androgen is capable of inducing primer pheromone activity in the female and suggest that the synthesis pathway of the male effect pheromone exists in both sexes in the goat.
\end{abstract}

Key words: Dihydrotestosterone (DHT), Goat, Male effect, Pheromone, Testosterone

(J. Reprod. Dev. 53: 829-834, 2007)

$\mathbf{T}$ he "male effect" is a well-documented phenomenon in sheep and goats [1] in which the primer pheromone produced in sexually mature males increases the luteinizing hormone (LH) pulse frequency and induces estrus in recipient females during the anestrous period [2-4].

Accepted for publication: March 13, 2007

Published online: April 26, 2007

Correspondence: Y. Kakuma (e-mail: kakuma@ntu.ac.jp)
The gonadotropin-releasing hormone (GnRH) pulse generator generates intermittent $\mathrm{GnRH}$ discharges into the portal vessels and thereby regulates the pulsatile $\mathrm{LH}$ secretion into the peripheral circulation [5]. Therefore, the central target of the male effect pheromone is thought to be the hypothalamic GnRH pulse generator.

We previously established a technique to monitor the electrophysiological manifestation of 
the hypothalamic GnRH pulse generator as multiple-unit activity (MUA) in Shiba goat [6]. Consequently, two studies demonstrated that exposure to the hair collected from mature male goats induced an immediate characteristic increase in the MUA (MUA volley) in female goats [7, 8]. Using the MUA technique as a bioassay system to assess the pheromone activity, Iwata et al. [9] demonstrated in castrated male goats that treatment with testosterone ( $\mathrm{T}$ ) for 28 days induced production of the male effect pheromone in the head skin, and that the pheromone activity in the skin sample disappeared within 14 days after cessation of the T treatment. Furthermore, the treatment with dihydrotestosterone (DHT), which has higher affinity with androgen receptors than $\mathrm{T}$, resulted in production of the pheromone not only in the head but also in the rump skins of castrated male goats $[10,11]$.

In the present study, we investigated whether androgen is also capable of inducing production of the male effect pheromone in female goats. Ovariectomized (OVX) goats were treated with either T or DHT and the pheromone activity in the head and rump skins was examined using the MUA technique. Because androgen treatment may cause several changes in masculine or feminine sexual behavior and aggressiveness in recipient female animals [12-14], we also observed behaviors of the androgen-treated OVX goats towards ovaryintact estrous goats.

\section{Materials and Methods}

\section{Animals}

Six female Shiba goats at the experimental station of the University of Tokyo (Kasama, Japan) were used. They ranged from 3 to 5 years of age and were $21.4-32.5 \mathrm{~kg}$ in body weight. They were ovariectomized (OVX) more than 2 months prior to the start of the study, and received androgen treatments. Three other ovary-intact goats of similar age and body weight were used only for behavior test. The OVX goats and ovary-intact goats were kept in separate indoor pens, and were maintained under natural day length and temperature conditions. They were fed twice daily with concentrate and hay. Water was freely available, except during behavior test. All goats had physical contact with mature male goats prior to this study.

In addition, five OVX goats treated with estradiol $17 \beta$ were used for the bioassay of pheromone activity. They were stereotaxically implanted with recording electrodes into the hypothalamus according to the procedure described before [6]. They were loosely tied to an individual stanchion, and maintained in a conditioned room (temperature $24 \mathrm{C}$, humidity 50\%, $12 \mathrm{~h}$ light), and fed daily with concentrate and hay and water $a d$ libitum.

All experiments in this study were approved by the Board for the Care and Use of Animals of the Graduate School of Agricultural and Life Sciences of the University of Tokyo, Tokyo, Japan.

\section{Experimental design}

First, a behavior test was conducted and the skin samples were collected from the OVX goat (OVX1). Silicone capsules containing DHT were then implanted into the goat. After 28 days, the second behavior test was conducted and the skin samples were collected $(\mathrm{OVX}+\mathrm{DHT})$. The DHT capsules were then removed. After a recovery period of 32 days, the same set of experiments was repeated using capsules containing $\mathrm{T}(\mathrm{OVX} 2$ and $\mathrm{OVX}+\mathrm{T})$. The dosage and duration of the androgen treatment and the recovery period between the two treatments were determined based on our previous study in castrated male goats [9].

\section{Implantation of androgens}

Six silicone capsules containing $1 \mathrm{~g}$ of either crystalline DHT (Wako Pure Chemicals, Osaka, Japan) or T (Wako) were subcutaneously implanted into the subscapular region of the OVX goat under light anesthesia. One capsule was composed of two silicone rubber sheets $(5 \times 5 \mathrm{~cm}$; Tigers Polymer, Osaka, Japan).

\section{Skin samples and bioassay for pheromone activity}

Skin samples $(10 \times 5 \mathrm{~mm})$ were collected from the head and rump regions under light anesthesia. Samples were then frozen at $-20 \mathrm{C}$ until extraction. For extraction, each skin sample was trimmed and put in a 2-ml screw-top glass vial. After adding diethyl ether, the sample was homogenized using an ultrasonic homogenizer (Tomy, Tokyo, Japan) to extract the fat-soluble components. The ether layer was recovered by decantation and was allowed to evaporate in a dry bath at $42 \mathrm{C}$ under nitrogen gas. 
The vial was purged with nitrogen, sealed with a Teflon cap, and kept at -20 C until assayed.

The pheromone activity was examined as described previously [7-11]. In brief, on the day of bioassay, the sample was dissolved in diethyl ether. A wiping paper $(12 \times 21.5 \mathrm{~cm})$ was soaked in it, and was allowed to dry for a few minutes. The goat with the MUA electrode was then exposed to the paper containing the sample material for $2 \mathrm{~min}$ while recording the MUA continuously. When an MUA volley occurred within the 2-min exposure period, the sample was considered to contain the male effect pheromone activity. Male goat hair or a paper soaked in diethyl ether was used for the positive or negative control, respectively, of the bioassay.

\section{Behavior test}

Two days prior to the behavior test, three ovaryintact goats were intramuscularly injected with 3 mg of prostaglandin F $2 \alpha$ (PG, Panaseran F) to induce estrus on the day of the test. The OVX goat was habituated to a test pen $(2.4 \times 3.4 \mathrm{~m})$ prior to the test.

On the day of the behavior test, a light open-top square cage $(0.95 \times 1.2 \mathrm{~m}, 0.9 \mathrm{~m}$ in height $)$ surrounded by a net was placed at the corner of the test pen. One OVX goat with or without the androgen treatment was put in the cage, and three estrous goats were introduced in the pen. Behaviors of the estrous goats towards the OVX goat were monitored for $10 \mathrm{~min}$. Then, the OVX goat was released from the cage to allow direct contacts between the animals. Behaviors of both the OVX goat and the estrous goats were observed for $10 \mathrm{~min}$. After observation, all goats were removed from the pen, and the floor of the pen was cleaned with water and $70 \%$ ethanol to remove water- and fat-soluble excreta. After a 10-min interval, the behavior test was repeated using the other OVX goat and the same three estrous goats. All six OVX goats were subjected to the behavior test with or without the DHT and T treatments, and the order of the behavior test was randomized in the OVX goats. Behaviors were recorded using two video recorders throughout the test.

\section{Data analyses}

Behaviors analyzed in the OVX goat included courtship, mounting and aggressive behaviors towards the estrous goat when the OVX goat was being released from the cage. Those analyzed in the estrous goat were non-aggressive stay when the OVX goat was being restricted in the cage and tail swishing when the OVX goat was being released from the cage. The non-aggressive stay was defined as a period when the head of the estrous goat was within $30 \mathrm{~cm}$ from the cage. The tail swishing was a behavior displayed by the goat in estrus. The courtship behavior was defined as any sexual and non-aggressive approaches by the OVX goat towards the estrous goat, including chasing, snorting, sniffing of the anogenital area or neck, kicking and twisting. The aggressive behavior was mainly head butting.

Behavior was analyzed using videotapes and a computer-based behavior analyzing system (CIE12; Toyo Sangyo, Toyama, Japan). Duration of each behavior displayed by individuals in each behavior test was calculated, and values were averaged within the groups in each treatment. Data are expressed as mean \pm SEM.

The duration of each behavior was compared using two-way analysis of variance (ANOVA) with repeated measures on the two treatment types ( $T$ and DHT), and two occasions (OVX and OVX+T or DHT). The level of statistical significance was set at 0.05 .

\section{Results}

The skin samples were taken from the head and rump regions of six OVX goats before and at the end of the androgen treatments, and the male effect pheromone activity in their ether extracts was examined by bioassay using the MUA technique. A typical example of the MUA during the bioassay is shown in Fig. 1, and Table 1 summarizes the results of the bioassay. Before the DHT treatment (OVX1), neither the head nor rump skin samples contained pheromone activity. Treatment with DHT for 28 days $(\mathrm{OVX}+\mathrm{DHT})$ induced pheromone activity in the head skin sample of all six goats. The rump skin sample of two OVX+DHT goats also contained pheromone activity. Thirty-two days after removal of the DHT capsules (OVX2), pheromone activity had completely disappeared in the skin samples from both the head and rump regions. Treatment with $\mathrm{T}$ for 28 days $(\mathrm{OVX}+\mathrm{T})$ resulted in induction of pheromone activity in the head skin sample of five goats. In two out of those five OVX+T goats, 


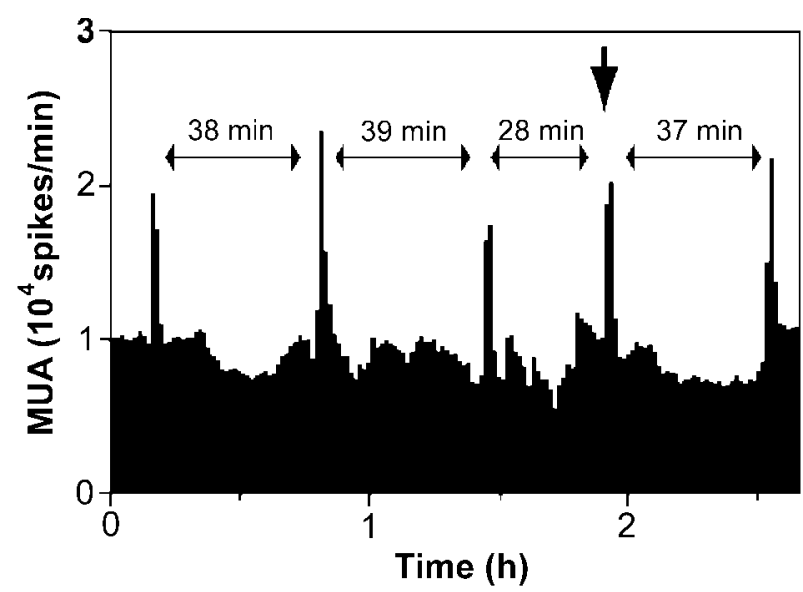

Fig. 1. Typical example of MUA during bioassay in an OVX goat treated with estradiol. MUA volleys usually occurred at almost constant intervals of 37-39 min in this goat. Sample was always applied at $2 / 3$ of the constant interval (in this case, $26 \mathrm{~min}$ ) after one of the regularly occurring MUA volleys (arrow). When a MUA volley occurred within the 2-min exposure period as shown here, that sample was considered to contain pheromone activity. When the volley occurred at a regular interval, sample was considered to have no pheromone activity. pheromone activity was also observed in the rump skin sample. In one OVX goat, pheromone activity was induced in the rump skin after both $\mathrm{T}$ and DHT treatments, but only after either $\mathrm{T}$ or $\mathrm{DHT}$ treatment in two OVX goats.

The results of the behavior tests are summarized in Table 2. Treatment of the OVX goat with T resulted in significant induction of non-aggressive approaches such as chasing, snorting, sniffing of the anogenital area or neck, kicking, or twisting, towards the estrous goat. The OVX goat with T treatment also showed mounting behavior towards the estrous goat, while the DHT treatment did not induce such behavior in the OVX goat. The aggressive behavior of the OVX goat was not significantly altered by either androgen treatment. The tail swishing behavior of the estrous goat towards the T-treated OVX goat tended to increase $(\mathrm{P}<0.05$ for treatment; $\mathrm{P}<0.1$ for time), whereas the non-aggressive stay of the estrous goat did not differ between treatments.

\section{Discussion}

Signoret et al. [12] reported that the presence of T-

Table 1. Pheromone activity in skin sample of OVX goats treated with DHT or T

\begin{tabular}{|c|c|c|c|c|}
\hline \multirow[b]{2}{*}{ Region } & \multicolumn{4}{|c|}{ No. of positive samples / No. of total sapmles } \\
\hline & OVX1 & $\mathrm{OVX}+\mathrm{DHT}$ & OVX2 & $\mathrm{OVX}+\mathrm{T}$ \\
\hline$\overline{\text { Head }}$ & $0 / 6$ & $6 / 6$ & $0 / 6$ & $5 / 6$ \\
\hline Rump & $0 / 6$ & $2 / 6$ & $0 / 6$ & $2 / 6$ \\
\hline
\end{tabular}

Table 2. Effects of androgen treatments on each behavior

\begin{tabular}{lcccc}
\hline & \multicolumn{3}{c}{ Treatment } \\
\hline Types of behavior & OVX1 & OVX+DHT & OVX2 & OVX+T \\
\hline $\begin{array}{l}\text { Behaviors of OVX goat }(\mathrm{n}=6) \\
\text { towards estrous goat }\end{array}$ & & & & \\
$\quad$ Courtship behavior & $1.5 \pm 0.6$ & $19.3 \pm 8.1$ & $65.4 \pm 18.4$ & $224.3 \pm 34.7$ \\
$\quad \begin{array}{l}\text { Mounting behavior } \\
\text { Aggressive behavior }\end{array}$ & $25.2 \pm 6.8$ & $36.7 \pm 26.2$ & $20.6 \pm 7.9$ & $3.0 \pm 30.7$ \\
Behaviors of estrous goat $(\mathrm{n}=3)$ & & & & $3.2 \pm 3.2$ \\
towards OVX goat & & & & \\
$\quad$ Non-aggressive stay & $481.4 \pm 12.5$ & $430.1 \pm 50.9$ & $492.0 \pm 29.6$ & $438.2 \pm 53.8$ \\
$\quad$ Tail swishing & $16.9 \pm 3.9$ & $20.5 \pm 4.0$ & $40.1 \pm 11.5$ & $134.7 \pm 54.0$ \\
\hline
\end{tabular}

Values (mean \pm SEM) are cumulative duration $(\mathrm{sec})$ in 10-min observation. -: Behavior not observed. a: $\mathrm{P}<0.05$ for time, treatment and interaction. $\mathrm{b}: \mathrm{P}<0.1$ for time and $\mathrm{P}<0.05$ for treatment. 
treated ewes resulted in induction of out-of-season ovulation in other ewes within the same flock. Similarly, Mellado and Hernández [13] showed that female goats treated with $\mathrm{T}$ were able to induce estrus in other female goats. Although these reports imply production of the male effect pheromone in T-treated females, factors other than the pheromone, such as masculine-type behaviors displayed by the T-treated females, could not be excluded. In the present study, we showed that the head skin extract of the T- or DHT-treated female goat induced a rapid occurrence of the MUA volley as shown in Fig. 1. Since this volley represents the electrophysiological manifestation of the GnRH pulse generator, the result suggests that male effect pheromone activity was induced in the female skins by androgens.

The pheromone production ability of T and DHT in the head skin of the female goat was comparable with that of the castrated male goat treated with $\mathrm{T}$ [9] or DHT [10]. On the other hand, the action of androgens in the rump skin appears slightly different between males and females. $T$ induced pheromone activity in the rump skin in two female goats, while it had no effect in the male goat [9]. DHT induced pheromone activity in the rump skin in all males [10], but only in two out of six female goats. These results suggest that although the synthesis pathway of the primer pheromone exists in both male and female, the expression of substances involved in the synthesis pathway, such as $5 \alpha$-reductase and androgen receptors [10], is regionally different between sexes in the goat.

Proceptive behaviors displayed in estrous female goats towards sexually mature male goats, such as approaching, tail swishing and body sniffing [15, 16], are considered to be induced partially by releaser pheromones of the male. It has been shown that the hair of the head and neck of the mature male goat contains releaser pheromones, such as 4-ethyl octanoic acid [17]. In the present study, although the tail swishing behavior increased, the non-aggressive stay of the estrous goat was unchanged by androgen treatments of the OVX goat. Therefore, unlike the primer pheromone, the production mechanism of the releaser pheromone may differ between sexes in the goat.

It is generally thought that treatment of females with androgen induces feminine-rather than masculine-type behaviors in mammals including sheep [18] and goats [14, 19]. However, we observed only masculine sexual behaviors such as courtship and mounting behaviors in the OVX goat after $\mathrm{T}$ treatment. In this study, a relatively high dose of androgen (six silicone capsules containing 1 $\mathrm{g}$ of androgen) was administered to the OVX goat, and the treatment was maintained for a relatively long period (28 days). Although the reason is unclear, the experimental design may account for this discrepancy. In fact, it has been reported in the goat that T-treated castrated males and females display intense male sexual behaviors, such as insistent chasing, mounting, and sniffing the anogenital area of estrous females [13].

The action of $\mathrm{T}$ is mediated by either androgen receptors or estrogen receptors after it is aromatized to estrogen, while that of DHT is mediated by only the former. Because the male effect pheromone activity was induced by $\mathrm{T}$ and DHT in a similar manner, androgen receptors might be involved in the pheromone synthesis in the goat. On the other hand, it appears that the expression of masculine-type sexual behaviors in the female goat largely depends on estrogen receptors, because the masculine-type behaviors were observed for a longer period with the $\mathrm{T}$ treatment compared with the DHT treatment. In various male animals, it has been demonstrated that both androgen and estrogen receptors participate in the control of the masculine-type behaviors [19-22].

In conclusion, we demonstrated in the present study that treatment of OVX goats with androgen induced the male effect pheromone activity in the head and rump skins, suggesting that the synthesis pathway of the primer pheromone exists in the male and female in the goat.

\section{Acknowledgements}

This study was supported by Grants-In-Aid for Scientific Research (15GS0306) from the Japan Society for the Promotion of Science and Grants-InAid for Animal Behavior Program from the Ministry of Agriculture, Forestry, and Fisheries, Japan. The authors thank Dr. Toru Sawazaki for providing animals from the colony of the University of Tokyo and Mr. Ryuji Sako for his assistance. 


\section{References}

1. Gelez H, Fabre-Nys C. The "male effect" in sheep and goats: a review of the respective roles of the two olfactory systems. Horm Behav 2004; 46: 257-271.

2. Chemineau P. Possibilities for using bucks to stimulate ovarian and oestrus cycles in anovulatory goats—a review. Livest Prod Sci 1987; 17: 135-147.

3. Claus R, Over R, Denhard M. Effect of male odour on LH secretion and the induction of ovulation in seasonally anoestrous goats. Anim Reprod Sci 1990; 22: 27-38.

4. Over R, Cohen-Tannoudji J, Dehnhard M, Claus $\mathbf{R}$, Signoret JP. Effect of pheromones from male goats on LH-secretion in anoestrous ewes. Physiol Behav 1990; 48: 665-668.

5. Karsch FJ. The hypothalamus and anterior pituitary gland. In: Austin CR, Short RV (eds.), Reproduction in Mammals: 3 Hormonal Control of Reproduction $2^{\text {nd }}$ ed, Cambridge: Cambridge University Press; 1984: 1-20.

6. Mori $\mathbf{Y}$, Nishihara $M$, Tanaka T, Shimizu T, Yamaguchi M, Takeuchi Y, Hoshino K. Chronic recording of electrophysiological manifestation of the hypothalamic gonadotropin-releasing hormone pulse generator activity in the goat. Neuroendocrinology 1991; 53: 392-395.

7. Hamada T, Nakajima M, Takeuchi Y, Mori Y. Pheromone-induced stimulation of hypothalamic gonadotropin-releasing hormone pulse generator in ovariectomized, estrogen-primed goats. Neuroendocrinology 1996; 64: 313-319.

8. Ichimaru T, Takeuchi Y, Mori Y. Stimulation of the $\mathrm{GnRH}$ pulse generator activity by continuous exposure to the male pheromones in the female goat. J Reprod Dev 1999; 45: 243-248.

9. Iwata E, Wakabayashi Y, Kakuma Y, Kikusui T, Takeuchi Y, Mori Y. Testosterone-dependent primer pheromone production in the sebaceous gland of male goat. Biol Reprod 2000; 62: 806-810.

10. Iwata E, Wakabayashi Y, Matsuse S, Kikusui T, Takeuchi Y, Mori Y. Induction of primer pheromone production by dihydrotestosterone in the male goat. J Vet Med Sci 2001; 63: 347-348.

11. Wakabayashi Y, Iwata E, Kikusui T, Takeuchi Y, Mori Y. Regional differences of pheromone production in the sebaceous glands of castrated goats treated with testosterone. J Vet Med Sci 2000; 62: 1067-1072.

12. Signoret JP, Fulkerson WJ, Lindsay DR. Effectiveness of testosterone-treated wethers and ewes as teasers. Appl Anim Ethol 1982; 9: 37-45.

13. Mellado M, Hernández JR. Ability of androgenized goat wethers and does to induce estrus in goats under extensive conditions during anestrus and breeding seasons. Small Ruminant Res 1996; 23: 3742.

14. Imwalle DB, Katz LS. Divergent roles for estrogens and androgens in the expression of female goat sexual behavior. Horm Behav 2004; 46: 54-58.

15. Okada M, Hamada T, Takeuchi Y, Mori Y. Timing of proceptive and receptive behavior of female goats in relation to the preovulatory LH surge. J Vet Med Sci 1996; 58: 1085-1089.

16. Billings HJ, Katz LS. Male influence on proceptivity in ovariectomized French-Alpine goats (Capra hircus). Appl Anim Behav Sci 1999; 64: 181-191.

17. Sugiyama T, Sasada H, Masaki J, Yamashita K. Sex-specific fatty acids and related substances involved in characteristic odor in goat sebum. In: Sagara Y, Seto K (eds.), Pheromones and Reproduction. New Jersey: Parthenon Publishing Group; 1990: 53-62.

18. Lindsay DR, Robinson TJ. Oestrus-inducing activity of testosterone in the ewe. Nature 1961; 192: 761-762.

19. Mellado M, Hernández JR. Ability of androgenized goat wethers and does to induce estrus in goats under extensive conditions during anestrus and breeding seasons. Small Ruminant Res 1996; 23: 3742.

20. Ball GF, Balthazart J. Andorogen metabolism and the activation of male sexual behavior: it's more complicated than you think! Horm Behav 2006; 49: 13.

21. Wood RI. Estradiol, but not dihydrotestosterone, in the medial amygdale facilitates male hamster sex behavior. Physiol Behav 1996; 59: 833-841.

22. Bakker J, Honda S, Harada N, Balthazart J. Restoration of male sexual behavior by adult exogenous estrogens in aromatase knockout mice. Horm Behav 2004; 46: 1-10. 